\title{
Preparação e resposta a desastres do Brasil na pandemia da COVID-19
}

\section{Karina Furtado Rodrigues ${ }^{1}$ \\ Mariana Montez Carpes ${ }^{1}$ \\ Carolina Gomes Raffagnato ${ }^{1}$}

1 Escola de Comando e Estado-Maior do Exército / Programa de Pós-Graduação em Ciência Militares do Instituto Meira Mattos, Rio de Janeiro / RJ - Brasil

Como a crise em saúde pública causada pela pandemia da COVID-19 ajuda a compreender o funcionamento do Sistema Nacional de Proteção e Defesa Civil (SINPDEC) nas fases de preparação e resposta a desastres em saúde no Brasil? A resposta a essa pergunta se dará por meio do seguinte objetivo geral: compreender o funcionamento do SINPDEC no enfrentamento à COVID-19, com ênfase na atuação do Ministério da Saúde (MS), órgão gestor de combate às ameaças em saúde. Para tanto, três objetivos específicos serão explorados: caracterizar a (doença) COVID-19 como evento em saúde pública com potencial causador de desastre, situar os conceitos de preparação e resposta na literatura de governança de desastres e identificar previsões legais e funcionamento da gestão de desastres no Brasil. A despeito das tensões decisórias no âmbito político, a burocracia profissional brasileira conseguiu garantir a ativação do sistema de governança de desastres relativa às fases de preparação e resposta. Contudo, sua ativação não foi suficiente para aplacar a crise, cujo agravamento expõe falhas nas fases de prevenção e mitigação de desastres, bem como a falta de uma resposta ao desastre em âmbito federativo.

Palavras-chave: COVID-19; gestão de desastres; Sistema Nacional de Proteção e Defesa Civil; saúde pública.

\section{Preparación y respuesta a desastres de Brasil en la pandemia de COVID-19}

¿Cómo la crisis de salud pública causada por la pandemia de COVID-19 ayuda a comprender el funcionamiento del Sistema Nacional de Protección y Defensa Civil (SINPDEC) en las fases de preparación y respuesta a desastres de salud en Brasil? La respuesta a esta pregunta se dará mediante el siguiente objetivo general de investigación: comprender el funcionamiento del SINPDEC en el afrontamiento a la COVID-19, con énfasis en el trabajo del Ministerio de Salud, organismo gestor del combate contra las amenazas a la salud. Con este fin, se explorarán tres objetivos específicos: caracterizar la COVID-19 como un evento de salud pública con el potencial de causar un desastre; situar los conceptos de preparación y respuesta en la literatura sobre gestión de desastres; e identificar las predicciones legales y el funcionamiento de la gestión de desastres en Brasil. Se argumenta que, a pesar de las tensiones políticas en la toma de decisiones, la burocracia profesional brasileña logró garantizar la activación del sistema de gestión de desastres relacionado con las fases de preparación y respuesta. Sin embargo, su activación no fue suficiente para aplacar la crisis, cuyo empeoramiento expone fallas en las fases de prevención y mitigación de desastres, así como la falta -e importancia- de una respuesta al desastre en ámbito federativo.

Palabras clave: COVID-19; gestión de desastres; Sistema Nacional de Protección Civil; salud pública.

\section{Disaster preparedness and response in Brazil in the face of the COVID-19 pandemic}

This article aims to understand how the National System of Protection and Civil Defense functions in response to COVID-19, with emphasis on the work of the Ministry of Health, which is the body responsible for tackling health threats. Three specific objectives were used: the first characterizes COVID-19 as a public health event that can represent a disaster; the second situates the concepts of preparedness and response in the disaster governance literature; the third identifies the jurisprudence and the functioning of disaster management in Brazil. The findings show that, despite the political decision-making tensions, the Brazilian professional bureaucracy managed to guarantee the activation of the disaster governance system related to the preparation and response phases. However, its activation was not enough to allay the crisis. The severity of the pandemic exposed flaws in the phases of disaster prevention and mitigation, as well as the lack of coordinated government response.

Keywords: COVID-19; Disaster Management; Brazilian National Civil Protection and Defense System; Public Health. 


\section{INTRODUÇÃO}

Rumores de uma "pneumonia misteriosa" surgiram em Wuhan, na China, em meados de novembro de 2019. No dia 31 de dezembro, a doença foi notificada à Organização Mundial da Saúde (OMS) (Observatório Militar da Praia Vermelha [OMPV], 2020a), e já nos primeiros dias de janeiro de 2020 o sequenciamento do RNA do vírus havia sido concluído por diversos pesquisadores ao redor do mundo. A conclusão era uma só: fora descoberta outra doença respiratória provocada por um novo vírus da família coronavírus, batizado de SARS-CoV-2, e a doença por ele provocada, da COVID-19.

A partir de então, três eventos fizeram com que a OMS alterasse o risco global da COVID-19, de moderado para alto, em 27 de janeiro de 2020. O primeiro foi a confirmação de que a doença poderia ser transmitida de maneira sustentada entre seres humanos (OMPV, 2020c). O segundo foi o registro da primeira morte pela COVID-19 na China, em 11 de janeiro (OMPV, 2020b). Por fim, a chegada da enfermidade a outros países (OMPV, 2020c). No dia 30 de janeiro, a OMS declarou Emergência de Saúde Pública de Importância Internacional (ESPII) (OMPV, 2020d).

Em 11 de março, a organização atualizou o status da COVID-19, que passou a ser considerada pandêmica (OMPV, 2020e), o que na prática significava que o vírus estava circulando em todos os continentes. O elemento mais importante, contudo, foi a declaração de ESPII em janeiro, porque ela traduz o entendimento quanto ao risco imposto pela doença ao mundo, apontando para a necessidade de ações coordenadas de combate. Dito de outra forma, a declaração da OMS era um convite a que os Estados preparassem seus mecanismos nacionais para gestão e resposta a tal desastre biológico.

A pandemia da COVID-19, mesmo que não tenha sido a primeira deste século ${ }^{1}$ e ainda esteja em curva de contaminação ascendente em alguns países, tem gerado impactos sem precedentes no convívio em sociedade. Não é possível precisar as consequências que ela terá em médio e longo prazos, mas sabe-se que, no curto prazo, o maior desafio tem sido a gestão do desastre (ver seção 3).

Diante desse cenário, o presente artigo se pergunta: como a crise em saúde pública causada pela pandemia da COVID-19 ajuda a compreender o funcionamento do Sistema Nacional de Proteção e Defesa Civil (SINPDEC) nas fases de preparação e resposta a desastres em saúde no Brasil? O objetivo geral do estudo é compreender como funcionou o sistema na resposta à COVID-19, com ênfase na atuação do Ministério da Saúde (MS), órgão gestor no combate às ameaças em saúde.

A operacionalização se dará por meio da caracterização da COVID-19 como evento em saúde pública com potencial causador de desastre, da localização dos conceitos de preparação e resposta na literatura de governança de desastres e da identificação de previsões legais e funcionamento da gestão de desastres no Brasil. O recorte temporal deste artigo se inicia com os primeiros relatos de pneumonia atípica na China e vai até a demissão do agora ex-ministro da Saúde, Luiz Henrique Mandetta.

A despeito das tensões decisórias no âmbito político, a burocracia profissional brasileira conseguiu garantir a ativação do sistema relativa às fases de preparação e resposta previstas no SINPDEC. Para a construção do argumento aqui oferecido, parte-se do pressuposto de que o país tem uma estrutura de governança de desastres que contempla medidas que vão desde a prevenção até a recuperação das áreas afetadas, como descrito na Política Nacional de Proteção e Defesa Civil (PNPDEC). Sendo o

\footnotetext{
${ }^{1}$ Em 2009, o mundo vivenciou a pandemia de Influenza A H1N1/09, uma variante do já conhecido vírus Influenza A H1N1. Apesar de nova, a gripe causada por esse vírus não teve implicações comparáveis com as da pandemia atual. Isso se deu porque, por se tratar de um vírus da gripe, foi possível utilizar os protocolos de tratamento já conhecidos. Além disso, a taxa de letalidade, assim como o tempo de recuperação dos infectados pelo H1N1, é inferior à do SARS-CoV-2.
} 
Brasil membro da Organização das Nações Unidas (ONU) e partícipe da OMS, é de responsabilidade do país internalizar, na forma de marcos legais adequados, os compromissos internacionais assumidos, como (a) as recomendações da OMS feitas em 2005 quanto à necessidade de os países fortalecerem, ou criarem, seus mecanismos de preparação e resposta a uma pandemia (ver seção 3) e (b) o Regulamento Sanitário Internacional (RSI) aprovado pela 58 assembleia Mundial da Saúde da OMS (ver seção 4).

Conclui-se que a fragilidade do país é estrutural, dada a ausência de um tratamento da saúde como tema estratégico, o que compromete desde as fases de prevenção e mitigação até as fases de resposta e recuperação do ciclo de desastres. ${ }^{2}$ Isso se viu refletido na descontinuidade da liderança do MS e no tensionamento político que marca a gestão da crise. Da mesma forma, o insulamento burocrático das estruturas especializadas em saúde e desastres no Brasil resistiu somente até certo ponto às pressões pela minimização da gravidade da crise.

O artigo está dividido em sete partes, incluindo esta Introdução. A segunda parte apresenta o instrumental metodológico escolhido: o process tracing. A terceira introduz o arcabouço teóricoconceitual da literatura de governança e do ciclo de gestão de desastres. A quarta trata da estrutura de governança de desastres de saúde brasileira, enquanto a quinta discorre sobre a ativação do sistema para o enfrentamento da pandemia no Brasil. A sexta recupera as escolhas metodológicas e o arcabouço teóricoconceitual, inferindo as dificuldades do funcionamento do SINPDEC, com base no sequenciamento cronológico da quinta seção. Por fim, na Conclusão, são debatidos os achados deste artigo e apresentados alguns caminhos para a continuação desta pesquisa, dando ênfase à avaliação das decisões tomadas.

\section{METODOLOGIA}

Neste artigo, optou-se pelo método de process tracing para operacionalizar a pesquisa e dar significado aos seus achados. A classificação mais difundida do process tracing divide essa metodologia entre teste e desenvolvimento de teoria (Checkel, 2008; George \& Bennett, 2005), ainda que alguns autores considerem a narrativa histórica um terceiro tipo de process tracing (George \& Bennett, 2005; Mahoney, 2015; Tannenwald, 2007) e outros proponham a explicação de resultados como a terceira variante do método (Beach \& Pedersen 2013).

Tais classificações, entretanto, deixam de fora um tipo mais simples, porém fundamental, de process tracing: a inferência descritiva, que se aproxima - mas que não pode ser entendida como um sinônimo - da narrativa histórica. Isso porque tanto os testes quanto o desenvolvimento teórico e as narrativas históricas têm como foco a dimensão causal dos fenômenos estudados. Assim, as inferências descritivas seriam um passo anterior no qual se busca selecionar e dar sentido aos fenômenos antes de analisá-los.

Dessa perspectiva metodológica, foca-se aqui exclusivamente no process tracing de inferências descritivas para compreender as limitações do manejo brasileiro à COVID-19, a despeito do correto funcionamento do SINPDEC e do consequente acionamento das fases de preparação e resposta à pandemia. A inferência descritiva, apesar de se aproximar da narrativa histórica, permite o estudo de casos empíricos do tempo presente (Bennett, 2015), mas não tem o compromisso de demonstrar os nexos causais que ligam condições iniciais a resultados. Nas inferências descritivas, o método se vale

\footnotetext{
${ }^{2}$ Em 2008, foi lançada a Política de Desenvolvimento Produtivo (PDP), que estabeleceu cinco áreas estratégicas, entre as quais a da saúde. Todavia, desde então, o que se verificou foi a ausência da conversão das diretrizes da PDP em políticas públicas de fomento a essa área.
} 
do estudo cirúrgico de uma sequência cronológica de eventos previamente definida, buscando nela evidências que suportem ou não os argumentos defendidos pela pesquisa (Collier, 2011). Assim, as inferências descritivas derivadas do process tracing não se pretendem generalizáveis, sendo, portanto, uma variante do método útil aos estudos de caso único, como o aqui almejado.

Bennett (2015) e Collier (2011) argumentam em favor da validade deste tipo de estudo, apesar de a notoriedade do process tracing ter se dado pela capacidade de gerar inferências causais (George \& Bennett, 2010; Mahoney, 2015). Todavia, de acordo com Bennett (2015), as inferências descritivas são precondição - ainda que muitas vezes negligenciadas - para as inferências causais, que dependem do domínio anterior do fenômeno a ser analisado. Tal domínio deriva do conhecimento vertical e sistemático do caso empírico.

Apenas para que fique clara a diferenciação e a codependência entre as formas de process tracing, cabe aqui caracterizar a inferência causal. Como bem explica Checkel (2006), o process tracing, em sua forma analítica, busca a identificação dos mecanismos causais das variáveis explicativas. Isso é possível porque, como o próprio nome revela, trata-se de uma metodologia de mapeamento de processos. Beach e Pedersen (2013) discordam da proposição de Checkel - e é seguido por George e Bennett - sobre a relação entre o process tracing e o processo como recorte empírico de um contínuo histórico, fazendo a defesa de um process tracing que permita um exercício analítico focado em momentos específicos, possibilitando a visualização do mecanismo causal de interesse (Beach \& Pedersen, 2013; Beach, 2016).

Dado que o presente artigo constitui a publicação da primeira fase de uma agenda de pesquisa sobre governança de desastres no Brasil, justifica-se que nele o foco seja a descrição dos eventos, concomitantemente à identificação dos óbices que serão analisados nas fases posteriores da pesquisa. Cumpre ainda observar a relevância desse tipo de process tracing para além do debate acadêmico de testagem ou geração de hipóteses.

Bennett (2015, p. 4, tradução nossa) defende a aplicação do process tracing como metodologia que auxilia tomadores de decisão a "fazerem correções em meio ao percurso de pesquisa com a ajuda do process tracing, atualizando a expectativa de resultados à luz de novas evidências sobre o funcionamento das políticas como planejado"'3. Sua observação lança luz sobre dois aspectos caros à presente pesquisa. O primeiro versa sobre as características próprias do estudo de políticas públicas que assumem a necessidade de fazer ajustes finos nas decisões conforme estas são realizadas. O segundo diz respeito ainda ao aspecto metodológico, já que o process tracing, por não ser um modelo fechado, permite ao pesquisador extrapolar o recorte cronológico estabelecido, lançando luz sobre momentos da tomada de decisão anteriores ao do fenômeno observado, cujas implicações se materializam no período observado. Especificamente no caso da presente pesquisa, ver-se-á que as (não) escolhas feitas pelo Brasil ainda nos primeiros anos do século XXI impactaram a capacidade do país em se preparar para (e responder a) um desastre como o atual.

Por fim, cabem apresentar algumas observações quanto à escolha do método e ao modo como ele permite a operacionalização da presente pesquisa. Como bem observaram George e Bennett (2005), o process tracing é uma metodologia que considera a complexidade do fenômeno social. Assim, o método trabalha com o conceito de equifinalidade, isto é, assume que os resultados observados dos

\footnotetext{
${ }^{3}$ Em Inglês, no original: "make mid-course corrections with the help of process tracing, updating expected outcomes in light of new evidence on whether policies are working as planned".
} 
fenômenos sociais podem originar de diferentes combinações de causas iniciais, sendo, portanto, cético à existência de causas singulares capazes de dar sentido à complexidade social.

Com isso em mente, e recuperando o debate apresentado nesta seção, o presente artigo oferece uma aproximação à discussão sobre a gestão de desastres no Brasil, tendo como foco as fases de preparação e resposta à COVID-19, sem, contudo, negar que parte das dificuldades atuais tenha se originado de decisões passadas que comprometeram as fases de prevenção e mitigação.

No que se refere à coleta de dados, o presente artigo se utilizou da clipagem de notícias realizada pelo Observatório Militar da Praia Vermelha (OMPV, 2020). A coleta foi feita com base na revisão das publicações, em sua maioria de acesso livre, das principais agências de notícia do mundo e dos jornais de maior tiragem no Brasil. ${ }^{4}$ Além disso, $\mathrm{o}$ artigo se apoia na literatura secundária sobre governança de desastres, na documentação que estrutura essa governança e nos documentos internacionais sobre saúde e desastres.

\section{ARCABOUÇO TEÓRICO-CONCEITUAL}

Pandemias como a da COVID-19 podem ser caracterizadas como desastres, ou seja, eventos atípicos de larga magnitude, que geram um esgotamento das capacidades individuais dos órgãos respondedores do país de ocorrência (Kiruthu, 2012). Os prognósticos sobre o surgimento desse tipo de desastre há muito existem na literatura, e desde o início do debate a questão sempre foi menos sobre se a pandemia ${ }^{5}$ ocorreria e mais sobre quando ocorreria (Enserink, 2004). Evidência disso é que, desde 2005, em decorrência da Síndrome Respiratória Aguda Grave (SARS-CoV-2), já havia uma série de recomendações da OMS para que os países se preparassem para tal evento.

O relatório do secretariado executivo da organização, lançado nesse mesmo ano e intitulado Strenthening pandemic influenza preparedness and response, já afirmava que esse evento foi o mais próximo de uma pandemia ${ }^{6}$ que o mundo chegara desde $1968 .{ }^{7}$ Nesse contexto, tornava-se premente o fortalecimento (ou a elaboração) de planos nacionais e das estruturas do ciclo de gestão de desastres com base numa lógica de pensamento estratégico, o que inclui assegurar a capacidade produtiva de vacinas, garantir a produção de insumos e avalizar a formação de capital humano.

Documentos estabelecendo prioridades gerais de preparação para desastres, controle e redução de riscos - os quais incluem desastres pandêmicos - também foram elaborados mais recentemente. É o caso do Marco Sendai para a Redução do Risco de Desastres 2015-2030, redigido pelo Escritório das Nações Unidas para a Redução dos Riscos de Desastre (UNISDR) (Etinay, Egbu, \& Murray, 2018). Nesse documento, o Escritório estabelece quatro prioridades de ação para os Estados: compreender os riscos dos desastres, fortalecer a governança do risco dos desastres para gerenciar tal risco, investir na criação de resiliência para a redução dos riscos e aumentar a preparação para casos de desastre, possibilitando uma resposta eficaz e celeridade na fase de recuperação, reabilitação e reconstrução (UNISDR, 2015).

\footnotetext{
${ }^{4}$ AFP, EFE, Reuters, BBC, G1, Deutsche Welle, El País e CNN.

${ }^{5}$ Para o caso brasileiro, ver art. 144 da Constituição Brasileira de 1988.

${ }^{6}$ Endemia se refere a doenças de presença contínua em determinada área geográfica - por exemplo, a malária nas regiões de floresta tropical. Os surtos dizem respeito a um aumento inusitado do número de casos de uma doença em determinado período e área. Já as epidemias são caracterizadas pelo acometimento de uma grande população por uma doença, atingindo uma vasta área geográfica. Por fim, as pandemias caracterizam o transbordamento da epidemia para além das fronteiras nacionais, sendo sua ocorrência registrada em diversos continentes.

${ }^{7}$ A data se refere à epidemia de gripe aviária, batizada de gripe de Hong Kong.

${ }^{8}$ UNDRR na sigla em inglês, que já respondeu pela sigla UNISDR.
} 
As ações prioritárias sugeridas pelo UNDRR podem assumir formas diferentes a depender do tipo de desastre ocorrido. A OMS os distingue em quatro tipos: naturais, biológicos, tecnológicos e societais. Exemplos de desastres naturais são terremotos, tsunamis, ciclones, secas e inundações. Os tecnológicos se diferenciam dos primeiros porque decorrem de erro humano, como o que levou ao acidente nuclear em Fukushima, além de desabamento de prédios e outras estruturas, acidentes aéreos e vazamentos químicos. Exemplos de desastres biológicos são epidemias, infestações e pestes. Por fim, os societais envolvem conflitos ou atos intencionais como terrorismo, ataques cibernéticos, entre outros (Do, 2019; OMS, 2011; Quarantelli, Lagadec, \& Boin, 2007).

De acordo com essa classificação, a pandemia da COVID-19 é um desastre biológico. No entanto, seria possível acrescentar que, ainda que o surgimento de uma doença seja um fenômeno natural, práticas humanas - que vão do desmatamento ao consumo indiscriminado de carne de caça - têm gerado desequilíbrios ecossistêmicos, aumentando a probabilidade de surgirem novas doenças de natureza zoonótica. ${ }^{9}$ Adiciona-se a isso a grande circulação de pessoas ao redor do mundo como consequência do avanço tecnológico. Há ainda em muitos países a incidência de um caráter societal ao desastre, já que grandes parcelas da população não têm acesso a saneamento básico e habitam estruturas precárias que impossibilitam o isolamento, sendo impelidas a quebrá-lo para manter a subsistência (Lima, 2014).

Assim, a pandemia da COVID-19 poderia ser definida como um desastre biológico com elementos tecnológicos e societais atuantes em sua propagação. Esse tipo de desastre pode ser denominado como uma "ruptura social transsistêmica" (trans-system social rupture, na terminologia sugerida por Quarantelli et al., 2007), que, por sua escala, por seus impactos e por um excesso de informações e desinformações, aumenta a probabilidade de amplificação social da tragédia. Em outras palavras, a percepção da crise pode ser distorcida dadas as características psicológicas, sociais, institucionais e culturais da área afetada.

Frente a um problema tão complexo, cumpre considerar a governança ${ }^{10}$ de desastres e como ela incide no ciclo de gestão destes. Nessa governança, parte-se do pressuposto de que "somente a variedade destrói a variedade" (Kooiman, 1999, tradução nossa). Isso quer dizer que esses problemas têm múltiplas origens, o que faz com que somente a atuação conjunta e coordenada de várias soluções e instituições seja capaz de aplacar o problema não só na questão da saúde, mas também nos impactos que a pandemia traz às dimensões econômicas, sociais e ambientais do evento (Börzel, 2011; Zurita, Cook, Harms, \& March, 2015).

Como cada tipo de desastre suscita uma diferente gama de especialidades, no entanto, muitas vezes a atuação inicial de uma área específica é preponderante. No caso da pandemia da COVID-19, como se trata de um desastre biológico, atuação primária é a da área da Saúde. A entrada de outros atores aparece como resultado de diagnóstico e planejamento iniciais que advêm dessa área específica.

O ciclo de gestão de desastres provê entendimento sobre os passos que devem ser tomados em cada uma das fases, incluindo aquelas iniciais que se sustentam em áreas específicas. Esse ciclo é o arcabouço analítico mais usado nos estudos sobre tragédias, tendo migrado ao longo do século XX de uma visão focada na resposta para outra ocupada com medidas de prevenção e mitigação (Coetzee \& Niekerk, 2012). Tanto a OMS quanto a PNPDEC utilizam cinco fases para definir o ciclo do desastre: prevenção, mitigação, preparação, resposta e recuperação, conforme mostra a Figura 1.

\footnotetext{
${ }^{9}$ Zoonoses ocorrem por spillover (ou saltos) entre espécies e se dão quando vírus ou bactérias presentes em animais hospedeiros "saltam" destes para seres humanos, tornando-se patógenos causadores de novas doenças (Dhiman \& Tiwari, 2018).

${ }^{10}$ Neste artigo, assumimos o conceito de governança debatido por Stoker (1998), que pressupõe uma rede de instituições públicas e privadas autônomas, num ambiente em que as fronteiras entre público e privado não são claras quanto à solução de problemas que só podem ser resolvidos com ação interdependente da rede.
} 


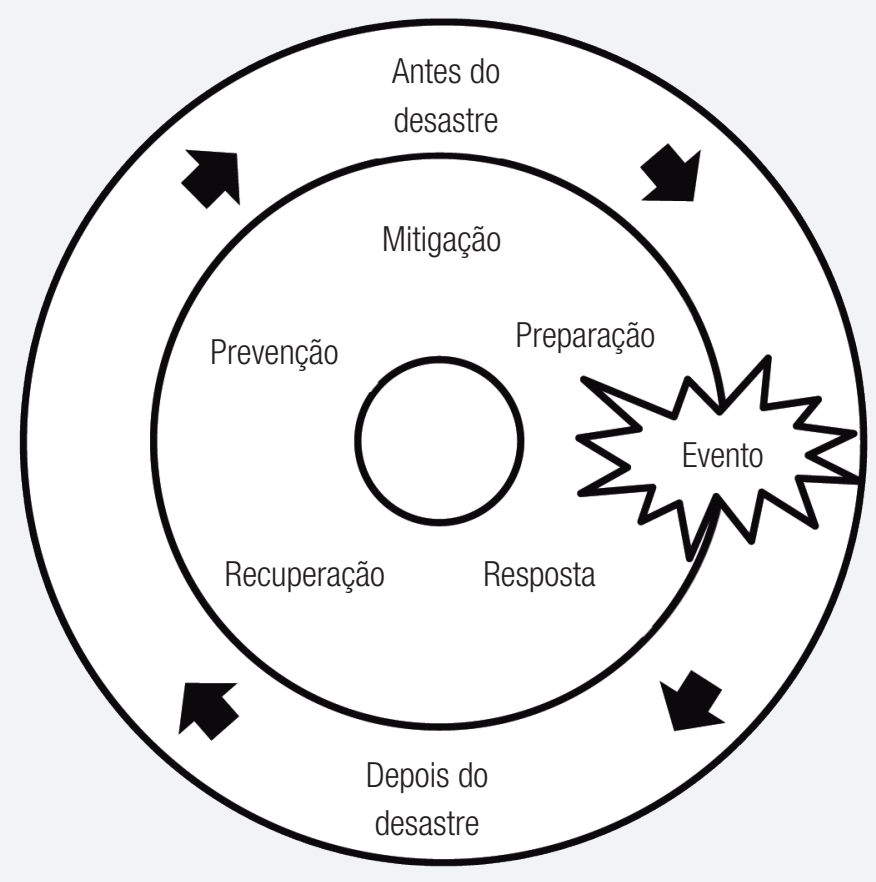

Fonte: Elaborado pelas autoras com base em PNPDEC (2012) e Wisner e Adams (2002).

As fases de prevenção, mitigação e preparação incluem muito do que é debatido na literatura de gestão de riscos de desastre (Matyas \& Pelling, 2014). A prevenção é focada em medidas permanentes com vistas a evitar a ocorrência do desastre, o que se dá por meio da elaboração de avaliações de risco, e de materiais educativos, bem como pela criação de códigos e zonas de risco. A mitigação se diferencia da prevenção por ser mais focada em criar resiliência nas estruturas e nos processos do que em evitar que a calamidade ocorra (Wisner \& Adams, 2002).

A fase de preparação consiste em atividades cujo objetivo é minimizar as perdas humanas e materiais de um evento iminente, possibilitar o pronto-emprego dos entes respondedores e organizar a remoção temporária de pessoas. Isso pode incluir elaboração de planos nacionais e legislação para a gestão de desastres; previsão de coordenação e colaboração nos níveis internacional, nacional e subnacional; formação e fortalecimento de pessoal e instituições respondedoras; e educação para a população, especialmente em áreas com maior risco de serem afetadas (Wisner \& Adams, 2002).

A resposta, por sua vez, é dependente de todas as fases anteriores, sobretudo da de preparação, que traz as bases para uma pronta-resposta. São condições necessárias a uma resposta adequada: disponibilidade de recursos humanos preparados, líderes com experiência, comunicação adequada, acesso a transporte e logística, bem como protocolos de ação para o tipo de emergência. As ações de resposta podem variar muito de acordo com o tipo de desastre. No caso das ameaças biológicas, o tempo da resposta é diferente do das ameaças naturais e tecnológicas, nos quais as primeiras 72 horas são decisivas para o resgate com vida das vítimas.

No caso de infestações, pestes e epidemias, o tempo da resposta depende da capacidade do Estado de conter ou controlar a disseminação do agente biológico, sendo, portanto, o tempo da resposta 
dilatado. Por fim, a fase de recuperação - ou, de acordo com a OMS, de reabilitação, reconstrução e recuperação - consiste em ações que, passada a emergência, visam ao retorno da normalidade. Mais uma vez, o tempo de recuperação é distinto no caso das ameaças biológicas, que é diretamente proporcional ao tempo necessário para a recuperação.

Ao avaliar as fases de preparação e resposta, há uma consequente avaliação da estrutura que as antecede - as de prevenção e mitigação, que geraram planos e legislações pertinentes a desastres. Além disso, uma preparação adequada é condição necessária e insuficiente para que a resposta também o seja, o que justifica a relevância do mapeamento proposto no presente estudo.

Como signatário da ONU, o Brasil é um dos 196 países nos quais vigora, desde 2007, o RSI, aprovado na 58 Assembleia Mundial de Saúde da OMS. O texto traz instruções para prevenção e resposta a uma ESPII. De acordo com o RSI, essa emergência é caracterizada como "um evento extraordinário que, nos termos do presente regulamento, é determinado como: (a) constituindo um risco para a saúde pública para outros Estados, devido à propagação internacional de doença e (b) potencialmente exigindo uma resposta internacional coordenada" (OMS, 2005, p. 9).

O RSI estipula que os países são responsáveis pelo aprimoramento das ferramentas de detecção e avaliação de eventos que ocorram em seus territórios, classificando-os em emergências de importância nacional ou internacional, e que devem comunicá-los à OMS quando houver o risco de disseminação para outros países - exatamente o que a China fez com a COVID-19. Além disso, os países precisam definir 'Pontos Focais Nacionais' (PFN) para o RSI. Entre suas atribuições estão a disseminação de informações aos setores administrativos do país e a consolidação das informações por ele enviada, incluindo os setores responsáveis por vigilância e notificação, pontos de entrada, serviços de saúde pública, clínicas, hospitais e outras repartições públicas (OMS, 2005).

A ênfase nos órgãos respondedores especialistas - de saúde, no caso deste artigo - não diminui a importância de ações que visem à governança do desastre em meio a uma pluralidade de outros problemas que advêm da mesma questão. Isso porque há muitos elementos que alteram a capacidade de ação dos Estados em cada uma das fases: o nível da capacidade burocrático-institucional dos entes respondedores, o nível de urbanização, a coexistência de problemas estruturais que aumentam a dificuldade de resposta, o nível de centralização/descentralização das decisões governamentais, o nível e a forma de acesso à informação dos cidadãos, o capital social de cada região e a diversidade de hábitos e modos de viver (Ahrens \& Rudolph, 2006; Kiruthu, 2012; Quarantelli, Lagadec, \& Boin, 2007; Rumbach, 2016; Tierney, 2012).

Por conseguinte, apesar de não ser o objetivo primário deste artigo, serão analisados indícios e caminhos para a governança com base no estudo da ativação do SINPDEC nas fases de preparação e resposta (ver seção 5). Com isso, a próxima seção explora como essa ativação é prevista na legislação. Em seguida, explora-se como ela ocorreu no caso da pandemia da COVID-19.

\section{A ESTRUTURA DA GESTÃO DE DESASTRES EM SAÚDE NO BRASIL}

Esta seção descreve a estrutura brasileira organizada pela PNPDEC, que envolve instituições como o MS e institui o SINPDEC. Subjaz a este debate o conceito de desastre discutido na seção 3 e como ele ganha corpo na legislação brasileira.

Em conformidade com o RSI e com o Marco Sendai, o marco legal brasileiro, materializado na Instrução Normativa no 2, de 2016, e na PNPDEC, traz a definição e o entendimento do que seja uma Emergência em Saúde Pública (ESP), a qual tem duas ações - situação de emergência (SE) e estado 
de calamidade pública $(\mathrm{CP})$-, subdivididas em três níveis hierarquizados pelo grau de intensidade do fenômeno. Respectivamente, trata-se de (1) evento que causa danos e prejuízos que implicam o comprometimento parcial da capacidade de resposta do Poder Público do ente federativo atingido (SE) e de (2) evento que afeta o comprometimento substancial da capacidade de resposta do Poder Público do ente federativo atingido (CP).

A diferença entre SE e CP é a intensidade e a gravidade dos prejuízos causados, comparativamente à capacidade de estados e municípios de lidar com esses danos (PNPDEC, 2017). Assim, como explica o Quadro 1, à SE correspondem os níveis I e II de intensidade do evento, sendo o nível III correspondente à CP. Já na esfera federal existe a declaração de Emergência em Saúde Pública de Importância Nacional (ESPIN), regulamentada pelo Decreto n ${ }^{\circ} 7.616$, de 2011, e pela Portaria $\mathrm{n}^{\mathrm{o}} 2.952$, do mesmo ano.

\section{QUADRO 1 CLASSIFICAÇÃO, CARACTERÍSTICAS E AÇÃO DE DESASTRE"11}

\begin{tabular}{|c|c|c|}
\hline Nível & Características & Ação \\
\hline $\begin{array}{l}\text { Nível I (pequena } \\
\text { intensidade) }\end{array}$ & $\begin{array}{l}\text { Somente danos humanos consideráveis cuja normalidade possa ser restabelecida } \\
\text { com recursos mobilizados em nível local. }\end{array}$ & SE \\
\hline $\begin{array}{l}\text { Nível II (média } \\
\text { intensidade) }\end{array}$ & $\begin{array}{l}\text { Danos e prejuízos suportáveis e superáveis pelos governos locais cuja } \\
\text { normalidade possa ser restabelecida com os recursos mobilizados em nível local } \\
\text { ou complementados com o aporte de recursos estaduais e federais, afetando a } \\
\text { capacidade do poder público local de responder e gerenciar a crise instalada. }\end{array}$ & SE \\
\hline $\begin{array}{l}\text { Nível III (grande } \\
\text { intensidade) }\end{array}$ & $\begin{array}{l}\text { Danos e prejuízos não superáveis e suportáveis pelos governos locais cujo } \\
\text { restabelecimento da normalidade depende da mobilização e da ação coordenada } \\
\text { das três esferas de atuação do SINPDEC e, em alguns casos, de ajuda internacional. }\end{array}$ & $\mathrm{CP}$ \\
\hline
\end{tabular}

Fonte: Adaptado de PNPDEC (2017).

Nota-se aqui a delegação de responsabilidades para cada ente da federação com base na gravidade do desastre, entendendo que, a depender da magnitude do evento, a coordenação da resposta com as demais entidades se faz necessária em função do esgotamento das capacidades instaladas. Assim, a gestão de desastres no Brasil sugere uma mobilização escalonada dos atores do SINPDEC conforme evolui o cenário.

A Lei ${ }^{\circ} 12.608$, de 2012, ${ }^{12}$ instituiu o SINPDEC. Essa legislação, atualizada em 2017, criou a Política Nacional de Proteção e Defesa Civil (PNPDEC). Até 2017, o documento se chamava Política Nacional de Defesa Civil, tendo sido a dimensão de proteção incluída apenas na versão de tal ano.

\footnotetext{
${ }^{11}$ A declaração de CP e SE nos níveis estaduais e municipais pode se dar concomitantemente à existência de uma ESPIN, pois cada uma dessas ocorrências prevê compensações financeiras ou amortizações de dívidas específicas e que precisam ser contempladas caso a caso. Para lista completa e atualizada de estados e municípios em ação de CP ou SE, ver site do Ministério do Desenvolvimento Regional. Para a legislação que regula as compensações respectivas a cada uma dessas ações, ver Lei Federal no 12.340 (2010), Decreto n 5113 (2004), Decreto $n^{\circ} 7.223$ (2010), Decreto no 84.685 (1980), Lei no 12.983 (2014) e Decreto-Lei n. 3.365 (1941).

${ }^{12}$ A Política Nacional de Defesa Civil (PNDC) foi instituída em 2007, pelo então Ministério da Integração Nacional - atualmente, Ministério do Desenvolvimento Regional. No entanto, somente em 2012 as diretrizes legais que orientam sua criação foram instituídas, quando sancionada a Lei ${ }^{\circ} 12.608$.
} 
A inserção da proteção indica um esforço para dar ênfase às fases de prevenção e mitigação do ciclo de gestão dos desastres, ainda que, como verificado no caso do enfrentamento à COVID-19, esta não tenha se materializado em ações. O SINPDEC, assim como a PNPDEC, está amparado numa abordagem sistêmica, atribuindo caráter interagência à governança de desastres no Brasil.

As ESPs - de importância municipal, estadual ou nacional - são de notificação compulsória, controlados pelo Centro de Informações Estratégicas em Vigilância em Saúde (CIEVS), órgão subordinado à Secretaria de Vigilância em Saúde (SVS) do MS (Portaria nº 30, de 2005). O CIEVS é o responsável por fazer a captação e a busca de notificações de caráter compulsório e analisar os dados e as informações relevantes. Ele também detecta, monitora e coordena a resposta aos ESPs em conjunto com as secretarias estaduais e municipais de saúde. Além disso, lida com as situações de crise, organizando o acompanhamento dos eventos que apresentem elevado potencial de disseminação ou riscos à saúde pública.

O plano de operação do PFN-RSI de 2016 diz que a SVS coordena a preparação e a resposta das ações de vigilância em saúde no âmbito da ESPIN e da ESPII, ficando sua operacionalização a cargo do CIEVS. Em suas ações, o plano prevê a detecção das ESPs e a adoção de medidas adequadas, além de vigilância, prevenção e controle de doenças transmissíveis, entre outras atribuições (Brasil, 2016). Da mesma forma, contempla o apoio a estados e municípios em situações de ESP.

A PNPDEC traz como marco legal para a governança de desastre em saúde pública a Lei nº 8.080. Em concordância com o plano de operação do PFN-RSI, "instituiu o SUS como direção única em cada esfera de governo (municípios, estados, Distrito Federal e União) e definiu o MS como gestor no âmbito da União". O SUS tem normas próprias para a atuação na gestão do risco de desastres, estabelecidas pelo MS, dispondo sobre responsabilidades, diretrizes para execução e financiamento das ações de vigilância em saúde, no âmbito do Sistema Nacional de Vigilância em Saúde e do Sistema Nacional de Vigilância Sanitária (PNPDEC, 2017).

O Guia de preparação e respostas do setor de saúde aos desastres, de 2015 (Freitas, 2018), diz que a preparação para o desastre se inicia muito antes de ele acontecer, por meio da elaboração e da sistematização de ações no Plano de Preparação e Resposta (PPR). De acordo com a PNPDEC, é de competência da SVS coordenar a preparação e a resposta das ações de vigilância em saúde na ESPIN e na ESPII. Para isso, a SVS adota planos de preparação, resposta, e elabora planos de contingência específicos, que precisam estar alinhados com o Plano de Resposta às Emergências em Saúde Pública (PRESP), aprovado em 2014. É ele quem dá as diretrizes para a atuação da SVS em tempo oportuno e de forma qualificada e cooperativa (Brasil, 2014; PNPDEC, 2017).

O PRESP sistematiza a resposta às emergências em saúde pública por meio de etapas a serem cumpridas num algoritmo de decisão (Anexo A - PRESP). Consta em tal Anexo a montagem de estruturas para lidar com a crise. Quando há uma notificação de rumor feita pelo CIEVS, uma resposta é feita pela ativação do Comitê de Monitoramento de Eventos (CME), que tem como objetivo a monitoração dos eventos de interesse à saúde pública. Se necessário, o decisor opta pela montagem do Centro de Operações de Emergência em Saúde (COES), composto pelas coordenações-gerais e pelos departamentos da SVS competentes e que tem por objetivo a articulação e a integração dos atores envolvidos para a resposta (Brasil, 2014).

Cabe ainda um destaque que diz respeito às particularidades do desastre causado pela COVID-19. A ocorrência de epidemias, em especial de doenças desconhecidas, pode contribuir para a decretação 
de ESPIN (PNPDEC, 2017). Doenças desconhecidas, como aquelas causadas por vírus da família coronavírus beta, afetam os protocolos de resposta, haja vista que seus padrões epidemiológicos - taxa de disseminação, letalidade e tipo contágio - ainda são indeterminados. Tais características afetam o tempo de preparação e resposta ao desastre (ver seção 3), dado que o evento nasce no esgotamento das capacidades individuais dos entes da federação. Como será debatido na seção 5 , apesar das características aqui apresentadas para a pandemia, o Brasil foi um dos únicos países do mundo a não coordenar nacionalmente a resposta ao desastre.

\section{DO SURGIMENTO DA DOENÇA NO BRASIL À DEMISSÃO DE MANDETTA}

Esta seção explora a ativação do sistema apresentado na seção 4 numa linha do tempo que compreende o período entre os primeiros casos de pneumonia atípica na China até a demissão do ex-ministro Mandetta, como marco de descontinuidade administrativa. Assim, buscar-se-á identificar as ações tomadas na ativação das fases de preparação e resposta a desastres prevista no SINPDEC, evidências de coordenação entre agências e como a estrutura foi ativada.

Com base no PRESP, o Brasil acompanhava a evolução da doença na China desde 12 de dezembro de 2019, quando ainda não estava claro se as pneumonias atípicas registradas em Wuhan eram em decorrência de uma doença desconhecida até aquele momento. Em 3 de janeiro de 2020, o CIEVS solicitou a "verificação de rumor" sobre a doença na China, primeiro passo (fase de preparação) previsto no PRESP para a ativação da resposta a um desastre em saúde. Em 10 de janeiro, um dia após a confirmação de que se tratava de um novo vírus, o Comitê de Monitoramento de Eventos (CME) foi acionado para monitorar o surto da COVID-19 no país asiático (PRESP, 2014).

Seis dias depois, a SVS publicou o primeiro boletim epidemiológico trazendo informações da nova pneumonia (MS, 2020a). A partir de então, todos os eventuais casos confirmados da COVID-19 no Brasil precisariam ser relatados ao CIEVS, a fim de que fosse possível obter dados acerca da epidemiologia da doença e sua eventual evolução no país. Assim, o dia 3 de janeiro marca o início do funcionamento da gestão de desastres em saúde no Brasil, referente à fase de preparação (PNPDEC, 2017). Em 22 do mesmo mês, um dia após a declaração da OMS quanto ao risco global moderado da COVID-19, o Brasil ativou o Centro de Operações de Emergências em Saúde Pública para o Novo Coronavírus (COE-nCoV), em nível de alerta I (PRESP, 2014; Croda et al., 2020).

Em 27 de janeiro, o Brasil anunciava o primeiro caso suspeito de infecção no país, fazendo com que o COE-nCoV alterasse o alerta nacional do nível I para o II (PRESP, 2014). Ainda no dia 27, a Portaria $n^{\circ} 74$ (Agência Nacional de Vigilância Sanitária [Anvisa], 2020) criou o Grupo de Emergência em Saúde Pública para a condução de ações sobre o novo coronavírus. No dia 30, foi criado o Grupo Executivo Interministerial de Emergência em Saúde Pública de Importância Internacional (GEI-ESPII) $^{13}$ (ver Decreto $\mathrm{n}^{\circ} 10.211$, de 2020), e, em 3 de fevereiro, o MS instituiu a ESPIN (ver a Portaria $n^{\circ} 188$, de 2020) e pôs em vigor o Decreto no 7.616, de 2011, e a Portaria no 2.952, também

\footnotetext{
${ }^{13} \mathrm{O}$ presente artigo não debate o papel desse comitê, o que extrapola os objetivos aqui propostos quanto ao entendimento da relação entre o SINPDEC e a gestão de desastres em saúde. Todavia, diversas demandas do MS têm sido feitas por meio desse comitê. Uma evidência disso é que toda a atuação das Forças Armadas em relação à área de saúde surge de requerimentos do MS ao comitê interministerial, à exceção da produção de hidroxicloroquina nos laboratórios das forças, a qual foi resultado de contato direto do MS com as forças singulares (Gröhs, Biavaschi, \& Rodrigues, 2020).
} 
de 2011. Por conseguinte, o COE-nCoV elevou para III o nível de alerta nacional em concordância com o PRESP (2014). No mesmo dia, o Decreto ${ }^{\circ} 10.212$ promulgou o Artigo $4^{\circ}$ do RSI, indicando a ativação da SVS/MS como o PFN-RSI no Brasil. Sua maior missão seria representar e notificar à OMS os eventos relacionados à pandemia.

A principal motivação para a declaração de ESPIN foi a necessidade de repatriação dos brasileiros que estavam em Wuhan. Assim, em 4 de fevereiro, a Lei no 13.979, de 2020, foi aprovada, trazendo as diretrizes sobre o período de quarentena ao qual os brasileiros repatriados de Wuhan seriam submetidos ao chegarem ao Brasil.

A confirmação do primeiro caso da COVID-19 no Brasil, em 26 de fevereiro de 2020, inaugurou uma nova fase do ciclo de gestão de desastre em saúde no país. Em resposta a isso, o MS lançou o protocolo de tratamento do novo coronavírus, em 2 de março (MS, 2020b). Ainda nesse sentido, dois dias depois, a Fundação Oswaldo Cruz (Fiocruz) começou a distribuir kits de testagem rápida (OMPV, $2020 \mathrm{~g}$ ), indicando um olhar atento do país ao comportamento internacional do vírus.

A partir de 29 de fevereiro, quando o Brasil apresentava apenas transmissão local do vírus (OMPV, 2020f), uma série de medidas de restrição do espaço aéreo (OMPV, 2020f) e fechamento parcial das fronteiras terrestres nacionais (OMPV, 2020f) foi adotada na tentativa de retardar, ainda que não fosse possível impedir, a circulação do vírus em todo o território nacional. Dando continuidade à montagem da estrutura brasileira de resposta ao desastre, em 16 de março, o Governo Federal estruturou o Comitê de Crise para Supervisão e Monitoramento dos Impactos da COVID-19 para lidar com as demandas operacionais da pandemia, tais como: utilização do Fundo Nacional de Segurança Pública; chamamento público para a aquisição de equipamentos médicos considerados estratégicos; e simplificação do processo para declaração de CP no território nacional (Decreto $n^{\circ} 10.277$, de 2020). Esse Comitê, inicialmente, não era previsto na governança de desastre, porém foi criado no âmbito do Governo Federal para manejo da crise.

Em 20 de março, a Portaria no 454 (2020) declarou estado de transmissão comunitária da COVID-19 no Brasil. No mesmo dia, o Senado Federal aprovou o Decreto Legislativo $n^{\circ} 6$ (2020), encaminhado ao Congresso pela presidência da República, que decretava Estado de CP em todo o território nacional. Essa foi, até então, a única ação de coordenação nacional proposta pela presidência. Cabe ainda dizer que a medida não reflete o entendimento da presidência quanto à necessidade de ações coordenadas nacionalmente para o enfrentamento à pandemia; demonstra apenas a preocupação em não incorrer em ações passíveis de serem tipificadas como crime de responsabilidade - isso porque o decreto permite que o Executivo gaste mais do que o previsto e desobedeça às metas fiscais para custear ações de combate à pandemia.

Um dia após decretada CP, o Centro de Operações Conjuntas para o emprego das Forças Armadas no combate à COVID-19 foi ativado. Por fim, em 31 de março, o então ministro da Justiça, Sérgio Moro, autorizou o uso da Força Nacional no combate à pandemia no país (OMPV, 2020i).

Paralelamente, no mesmo dia em que o Brasil declarava transmissão comunitária do vírus, em 29 de fevereiro, em pronunciamento em cadeia nacional, a presidência minimizava os possíveis impactos da COVID-19. Tal declaração marcou o início do descolamento entre as recomendações internacionais e o entendimento da burocracia técnica nacional, por um lado, e aquele que passaria a ser o entendimento presidencial, por outro, quanto à gravidade do tema (OMPV, 2020g).

O escalonamento do desgaste gerado por tal descolamento se refletiria também nas manifestações de prefeitos e governadores em favor do tratamento adequado que a pandemia demandava, em 
oposição aos posicionamentos sustentados pela presidência (OMPV, 2020e; OMPV, 2020h). No Executivo, entretanto, as discordâncias sobre os caminhos mais adequados ao manejo da pandemia tiveram seu auge na demissão de Mandetta e sua substituição por Nelson Teich, ${ }^{14} \mathrm{em} 17$ de abril de 2020 (OMPV, 2020j), marcando uma descontinuidade administrativa da gestão da crise. Para compreensão dos eventos, a Figura 2 mostra a cronologia das fases de preparação e resposta à pandemia.

\section{FIGURA 2 CRONOLOGIA DE PREPARAÇÃO E RESPOSTA À PANDEMIA DA COVID-19 NO BRASIL}

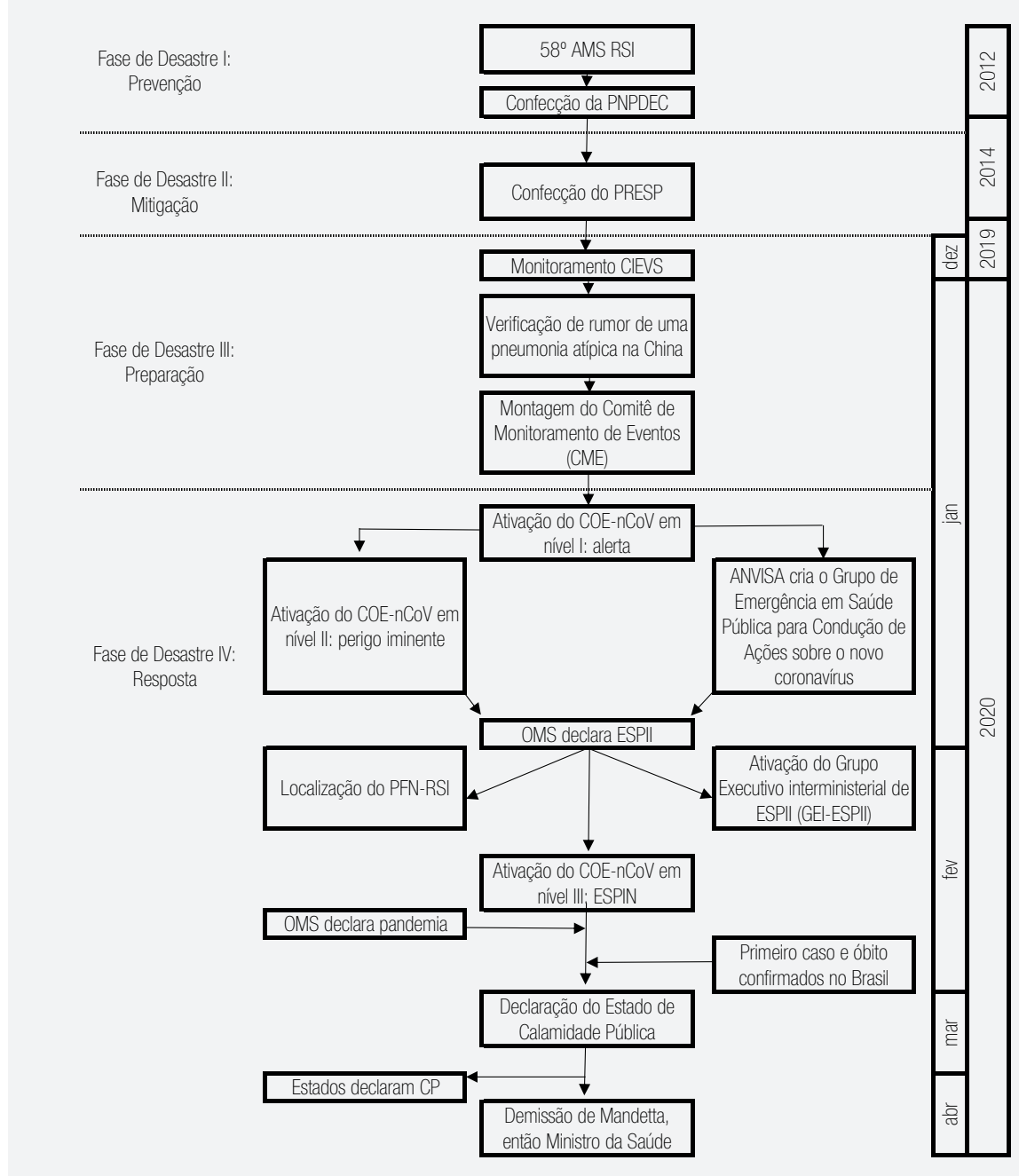

Fonte: Elaborada com base nos dados apresentados na seção 5.

\footnotetext{
${ }^{14} \mathrm{Na}$ data de publicação deste artigo, o ministro Nelson Teich já havia pedido demissão do cargo por discordar da maneira como a presidência da República conduzia o enfrentamento à COVID-19, tendo sido substituído interinamente pelo secretário-executivo do MS, general Eduardo Pazuello.
} 


\section{INFERÊNCIAS DESCRITIVAS COM BASE NO ESTUDO DE CASO}

Esta seção tem como objetivo recuperar os argumentos metodológicos introduzidos na seção 2 quanto à pertinência do método de inferências descritivas baseado no sequenciamento cronológico do fenômeno estudado. Apoiando-se nos conceitos de ciclo de desastres, na apresentação dos marcos legais brasileiros sobre a gestão dos desastres e na cronologia sobre o acionamento das fases de preparação e resposta à COVID-19, oferece alguns enunciados derivados do caso brasileiro. Tais enunciados não são generalizáveis; visam somente servir de guia para as etapas futuras da presente agenda de pesquisa sobre a governança de desastres no Brasil. São, portanto, enunciados propostos segundo a compreensão do caso empírico e têm alcance restrito a esse caso.

Dito isso, e com base no disposto nas seções anteriores, tem-se que, numa ESPII com fortes impactos sociais, econômicos e de saúde como a pandemia da COVID-19, a governança de desastres não evita o problema, mas o gere. Disso depende a diminuição de seus impactos em médio e longo prazos, podendo proporcionar uma recuperação mais rápida no pós-crise. Assim, os diagnósticos oferecidos pelo exame do caso brasileiro pretendiam encontrar uma gestão complexa, à altura de um fenômeno igualmente complexo. Todavia, o que se encontrou foi um quadro agravado por tensões políticas de minimização da magnitude do problema.

Desde o primeiro caso de contaminação pela COVID-19 confirmado no Brasil, uma série de medidas foi adotada pelo SINPDEC, com vistas a preparar o país para responder a uma possível crise em saúde pública decorrente da doença. A resposta imediata brasileira evidencia uma consonância entre as estruturas de governança de desastres nacional e internacional, já que as ações tomadas na ativação das fases de preparação e resposta sucederam temporalmente às decisões da OMS. A concomitância entre as recomendações internacionais e as decisões nacionais até esse momento sugerem a preponderância da avaliação da burocracia técnica especializada em detrimento de leituras políticas da conjuntura vivida. Pode-se inferir, pelo apresentado nas seções 4 e 5, que o Brasil tem um marco legal robusto no que tange a tragédias e desastres em saúde.

Se as estruturas de gestão de desastres foram devidamente ativadas, por que a curva epidemiológica no Brasil mostra resultados tão preocupantes? No momento em que se finalizava a escrita deste artigo, em 2 de julho de 2020, o número de mortes registradas por dia era de 1.252, e o número total de mortos já ultrapassava os 61.880 (COVID, 2020). Dada a limitação temporal do exame, as medidas aqui analisadas trataram de um contexto de registros de contaminados e mortos ainda gerenciável. No dia em que Mandetta foi demitido, contabilizavam-se 1.924 mortos e 30.425 contaminados (COVID, 2020). Portanto, o crescimento exponencial desses números mostra que medidas tomadas no início da crise foram insuficientes.

Isso ocorre porque a robustez legal não necessariamente se transmite em sua implementação. Contudo, o Brasil é um país experiente e com vasto histórico no combate a epidemias, como as mais recentes de dengue, zika vírus, chikungunya e febre amarela, mas também em campanhas de prevenção, como as de vacinação contra gripe, sarampo e rubéola, bem como no tratamento de doenças infecciosas graves, como a tuberculose. ${ }^{15}$ Além disso, o país conta com uma rede pública de saúde que, a despeito dos cortes de verba, é considerada um exemplo de atendimento universal no mundo (Gragnolati, Lindelow, \& Couttolenc, 2013). Pelo SUS, tratamentos caros e prolongados,

\footnotetext{
${ }^{15}$ Ver site do MS para lista completa de doenças com potencial epidêmico.
} 
como aqueles contra tuberculose, sífilis, hanseníase e leishmaniose, são oferecidos gratuitamente a todos os brasileiros, assim como o fornecimento gratuito de medicamentos para pacientes crônicos, como diabéticos, cardíacos e imunocomprometidos.

Apesar de o MS ter seguido as normas e as recomendações internacionais nas fases de preparação e de resposta inicial à pandemia, rapidamente se desvelou uma série de dificuldades na continuação sustentada da resposta delineada pela burocracia especializada. A primeira dificuldade se relaciona com as tensões decisórias acerca da maneira adequada de controlar a curva de contágio, a fim de evitar um colapso da rede pública. A exemplo disso, vale recuperar os sucessivos discursos presidenciais minimizando os impactos da doença e criticando o isolamento social, sob o manto da necessidade de manter a saúde econômica nacional (OMPV, 2020g).

Ademais, aumentando o tom de gravidade da pandemia no Brasil, o impasse político gerou conflitos entre a presidência da República, de um lado, e o Ministério da Saúde e os governos estaduais, de outro, com os últimos adotando medidas para o achatamento da curva de contaminação por COVID-19 à revelia do entendimento presidencial (OMPV, 2020g; OMPV, 2020h). O escalonamento da crise de gestão da pandemia protagonizado pela presidência levou à instituição de um 'Comando Conjunto do Planalto, o qual, na prática, criou uma estrutura gestora de apoio à presidência que acabou esvaziando o poder decisório do MS, reafirmando a descontinuidade administrativa representada pela demissão de Mandetta (Reuters, 2020).

As tensões políticas e decisórias advindas do posicionamento da presidência da República, num primeiro momento, não impactaram o funcionamento da burocracia especializada em saúde e da coordenação interministerial, de modo que não houve a paralisia decisória da máquina pública. Evidência disso foi a criação de comitês e centros interministeriais, as coletivas de imprensa diárias do ministro Mandetta e a ativação das coordenações no âmbito do PRESP e do COE-nCoV, entre outras.

Todavia o diagnóstico aqui oferecido sustente a tese de que prevaleceu o entendimento técnico para a ativação das fases de preparação e resposta à COVID-19, é importante ponderar que essa conjuntura sofreu as consequências das decisões (não) tomadas nas fases de prevenção e mitigação. Enfatizando a já mencionada ausência de um tratamento da saúde como tema estratégico, o país se viu em dificuldades para obter kits de testagem, materiais e insumos necessários aos testes de tipo RT-PCR, além de itens simples dos equipamentos de proteção individual e de outros, complexos, como os respiradores dos quais passaram a depender os pacientes graves (Barifouse, 2020).

A falta de recursos humanos gerou uma corrida por cursos emergenciais e convocação ad hoc de profissionais de todos os segmentos da saúde: dentistas, veterinários, fisioterapeutas e educadores físicos (Barifouse, 2020; Portaria n 639, 2020; Operação COVID-19, 2020). Como dito antes, essas dificuldades confirmam falhas nas fases de prevenção e mitigação do ciclo dos desastres, com considerável espaço para melhora.

Do estudo do caso brasileiro, infere-se que, a despeito da experiência do país no manejo de crises em saúde pública, a negligência nas fases de prevenção e mitigação gera dificuldades na execução da preparação e da resposta ao evento, dado o comprometimento estrutural de todo o ciclo dos desastres. Inversamente, se o Brasil tivesse implantado as diretrizes da 58 a Assembleia Mundial de Saúde e do Marco Sendai, bem como tratado a área de saúde sob uma perspectiva estratégica, teria conseguido gerir as fases de preparação e resposta de forma complexa, como o problema exige. Do mesmo modo, a politização da gestão de desastres agravou a já comprometida estrutura de gestão do desastre, refletindo no aprofundamento em vez da superação do fenômeno. Por fim, a força do 
insulamento burocrático das instituições especializadas, como "ilhas de racionalidade e especialização técnica" (Nunes, 2017) protegidas de variações políticas, foi testada pela pandemia e resistiu somente até certo ponto ao prolongado atrito com a presidência da República. Com isso, reflete-se sobre a necessidade de criar mecanismos que blindem áreas especializadas, em especial no caso de desastres, que afetam a vida de muitos cidadãos.

\section{CONSIDERAÇÕES FINAIS}

O presente artigo se perguntou como a crise em saúde pública causada pela pandemia da COVID-19 ajudou a compreender o funcionamento do Sistema Nacional de Proteção e Defesa Civil (SINPDEC) nas fases de preparação e resposta a desastres em saúde no Brasil. Como objetivo geral, pretendeu-se compreender o funcionamento do SINPDEC, tendo sido dada ênfase à atuação do MS, definido como órgão gestor no combate às ameaças em saúde. O estudo se circunscreveu ao período iniciado com os primeiros rumores de pneumonia atípica verificados pelo MS, terminando na demissão de Luiz Henrique Mandetta. A operacionalização do objetivo geral se deu pela caracterização da COVID-19 como evento em saúde pública com potencial causador de desastre, da localização dos conceitos de preparação e resposta na literatura de governança de desastres, sobre o que discorreu a seção, e da identificação das previsões legais e do funcionamento da gestão de desastres no Brasil, descritos nas seções 4 e 5, respectivamente. A variante do process tracing de inferências descritivas, apresentada na seção 2, foi usada como suporte metodológico a guiar a pesquisa entre os universos empírico e teórico-conceitual.

A despeito das tensões decisórias no âmbito político, a burocracia profissional brasileira conseguiu garantir a ativação do sistema relativa às fases de preparação e resposta previstas no SINPDEC. Todavia, como ofertado na forma de 4 enunciados dispostos na seção 6 , concluiu-se neste artigo que a fragilidade do país é estrutural. Isso porque se identificou a ausência de um tratamento da saúde como tema estratégico no Brasil, o que veio a comprometer todo o ciclo de gestão de desastres no enfrentamento da COVID-19, com agravamento do quadro identificado na fase de resposta. Assim, assistiu-se ao insulamento burocrático das estruturas especializadas em saúde e desastres, que resistiram somente até certo ponto às pressões pela minimização da gravidade da crise. A materialização disso veio com a demissão de Mandetta e a consequente descontinuidade da liderança do MS.

Este artigo foi concebido como parte de uma agenda de pesquisa que se propõe justamente a debater essas e outras questões concernentes à governança e ao ciclo de gestão de desastres no Brasil. A compreensão do tema, especificamente no caso da COVID-19, precisa ainda contemplar em futuras pesquisas uma discussão metodológica, usando agora as variantes causais do process tracing; uma análise sobre a fase de recuperação, ou seja, do gerenciamento da crise pós-COVID-19; a articulação entre o nível de resposta federal e os estaduais; a abordagem sistêmica proposta na PNPDEC e as dificuldades práticas que isso acarreta para a gestão de uma crise; os limites da transparência governamental durante as fases do desastre; a análise de risco de desastres versus o preparo dos respondedores; e, por fim, o debate entre desastres em saúde, zoonoses e o conceito de One Health proposto pelo OMS. 


\section{REFERÊNCIAS}

Ahrens, J., \& Rudolph, P. M. (2006). The importance of governance in risk reduction and disaster management. Journal of Contingencies and Crisis Management, 14(4), 207-220.

Barifouse, R. (2020, 09 de março). Brasil não adota novo critério da OMS que amplia busca por casos suspeitos. Época. Recuperado de https://epoca. globo.com/brasil/coronavirus-brasil-nao-adotanovo-criterio-da-oms-que-amplia-busca-por-casossuspeitos-24294775

Beach, D. (2016). It's all about mechanisms-what process-tracing case studies should be tracing. New Political Economy, 21(5), 463-472.

Beach, D., \& Pedersen, R. B. (2019). Process-tracing methods: Foundations and guidelines. Ann Arbor, Michigan: University of Michigan Press.

Bennett, A., \& George, A. L. (1997). Process tracing in case study research. Washington, DC: MacArthur Program on Case Studies.

Bennett, A. (2015). Using process tracing to improve policy making: The (negative) case of the 2003 intervention in Iraq. Security Studies, 24(2), 228-238.

Casa Civil. (2017). Manual de Proteção e Defesa Civil: A Política Nacional de Proteção e Defesa Civil. Brasília, DF: Ministério da Integração Nacional.

Centro Universitário de Estudos e Pesquisas sobre Desastres. (2012). Política Nacional de Defesa Civil. Florianópolis, SC: Universidade Federal de Santa Catarina.

Checkel, J. T. (2006). Tracing causal mechanisms. International Studies Review, 8(2), 362-370.

Coetzee, C., \& Van Niekerk, D. (2012). Tracking the evolution of the disaster management cycle: a general system theory approach. Jàmbá: Journal of Disaster Risk Studies, 4(1), 1-9.

Collier, D. (2011). Teaching process tracing: exercises and examples. PS: Political Science and Politics, 44(4), 823-830.

Croda et al. (2020). COVID-19 in Brazil: advantages of a socialized unified health system and preparation to contain cases. Journal of the Brazilian Society of Tropical Medicine, 53, e20200167.
Decreto Legislativo $n^{\circ}$ 6, de 20 de março de 2020. (2020). Reconhece, para os fins do art. 65 da Lei Complementar $\mathrm{n}^{\circ} 101$, de 4 de maio de 2000, a ocorrência do estado de calamidade pública, nos termos da solicitação do presidente da República encaminhada por meio da mensagem $n^{\circ} 93$, de 18 de março de 2020. Brasília, DF: Presidência da República.

Decreto $n^{\circ} 10.211$, de 30 de janeiro de 2020. (2020). Dispõe sobre o Grupo Executivo Interministerial de Emergência em Saúde Pública de Importância Nacional e Internacional (GEI-ESPII). Brasília, DF: Presidência da República.

Decreto $n^{\circ} 10.212$, de 30 de janeiro de 2020. (2020). Promulga o texto revisado do Regulamento Sanitário Internacional, acordado na 58 a Assembleia Geral da Organização Mundial de Saúde, em 23 de maio de 2005. Brasília, DF: Presidência da República.

Decreto $n^{\circ}$ 10.277, de 16 de março de 2020. (2020). Institui o Comitê de Crise para Supervisão e Monitoramento dos Impactos da COVID-19. Brasília, DF: Presidência da República.

Decreto $n^{\circ} 7.616$, de 17 de novembro de 2011. (2011). Dispõe sobre a declaração de Emergência em Saúde Pública de Importância Nacional (ESPIN) e institui a Força Nacional do Sistema Único de Saúde (FNSUS). Brasília, DF: Presidência da República.

Dhiman, C, R., Tiwari, A. (2018). Emergence of Zoonotic Diseases in India: A Systematic Review. Medical Reports \& Case Studies, 3(3), 1-8.

Do, X. B. (2019, junho). Return migration after the Fukushima Daiichi nuclear disaster: the impact of institutional and individual factors. Disasters, 44(3):569-595.

Enserink, M. (2004). Looking the Pandemic in the Eye. Science, 306(5695), 392-394.

Etinay, N., Egbu, C., \& Murray, V. (2018). Building Urban Resilience for Disaster Risk Management and Disaster Risk Reduction. Procedia Engineering, 212(2017), 575-582.

Freitas, C. M. (2018). Guia de preparação e respostas do setor saúde aos desastres. Rio de Janeiro, RJ: Fiocruz, Secretaria de Vigilância em Saúde.

George, A. L., Bennett, A., Lynn-Jones, S. M., \& Miller, S. E. (2005). Case studies and theory 
development in the social sciences. Cambridge, MA: MIT Press.

Gragnolati, M., Lindelow, M., \& Couttolenc, B. (2013). Twenty Years of Health System Reform in Brazil: An Assessment of the Sistema Unico de Saúde. Directions in Development--Human Development. Washington, DC: World Bank.

Instrução Normativa $n^{\circ}$ 2, de 20 de dezembro de 2016. (2016). Estabelece procedimentos e critérios para a decretação de situação de emergência ou estado de calamidade pública pelos Municípios, Estados e pelo Distrito Federal, e para o reconhecimento federal das situações de anormalidade decretadas pelos entes federativos e dá outras providências. Brasília, DF: Ministério da Integração Nacional.

Kiruthu, F. (2014). Book Review: Building Resilience: Social Capital in Post Disaster Recovery. Daniel P. Aldrich. University of Chicago Press, 2012. Governance, 1, 169-171.

Kooiman, J. (1999). Social-Political Governance. Public Management: An International Journal of Research and Theory, 1(1), 67-92.

Lei 12.608, de 10 de abril de 2012. (2012). Institui a Política Nacional de Proteção e Defesa Civil (PNPDEC); dispõe sobre o Sistema Nacional de Proteção e Defesa Civil (SINPDEC) e o Conselho Nacional de Proteção e Defesa Civil (Conpdec); autoriza a criação de sistema de informações e monitoramento de desastres; altera as Leis $\mathrm{n}^{\circ} 12.340$, de $1^{\circ}$ de dezembro de 2010, 10.257, de 10 de julho de 2001, 6.766, de 19 de dezembro de 1979, 8.239, de 4 de outubro de 1991, e 9.394, de 20 de dezembro de 1996; e dá outras providências. Brasília, DF.

Lei $n^{\circ} 12.340$, de $1^{\circ}$ de dezembro de 2010. (2010). Dispõe sobre as transferências de recursos da União aos órgãos e entidades dos Estados, Distrito Federal e Municípios para a execução de ações de prevenção em áreas de risco de desastres e de resposta e de recuperação em áreas atingidas por desastres e sobre o Fundo Nacional para Calamidades Públicas, Proteção e Defesa Civil; e dá outras providências. Brasília, DF: Presidência da República.

Lei $n^{\circ}$ 13.979, de 6 de fevereiro de 2020. (2020). Dispõe sobre as medidas para enfrentamento da emergência de saúde pública de importância internacional decorrente do coronavírus responsável pelo surto de 2019. Diário Oficial da União: seção
1, Brasília, DF: Agência Nacional de Vigilância Epidemiológica.

Lima, Y, Costa, E. (2014). Regulamento sanitário internacional: emergências em saúde pública, medidas restritivas de liberdade e liberdades individuais. Vig Sanit Debate, 3(1),10-18.

Mahoney, J. (2015). Process tracing and historical explanation. Security Studies, 24(2), 200-218.

Matyas, David; Pelling, Mark. (2014). Positioning resilience for 2015: the role of resistance, incremental adjustment and transformation in disaster risk management policy. Disasters, 39(s1), 1-19.

Ministério da Saúde. (2018). Guia para Investigações de Surtos ou Epidemias. Brasília, DF: Autor. Recuperado de https://www.saude.gov.br/images/ pdf/2018/novembro/21/guia-investigacao-surtosepidemias-web.pdf

Ministério da Saúde. (2020a). Boletim Epidemiológico. Situação epidemiológica da febre amarela no monitoramento 2019/2020. Brasília, DF: Secretaria de Vigilância Epidemiológica.

Ministério da Saúde. (2020b). Protocolo de Tratamento do Novo Coronavírus (2019-nCoV). Brasília, DF: Autor.

Ministério da Saúde. (2020c, 30 de abril). Painel Coronavírus. Brasília, DF: Autor. Recuperado de https://covid.saude.gov.br/

Ministério da Saúde. (2014). Plano de Respostas às Emergências em Saúde Pública. Brasília, DF: Autor.

Nunes, E. O. (2017). A gramática política do Brasil: clientelismo, corporativismo e insulamento burocrático. (5. Ed.). Rio de Janeiro, RJ: Garamond.

Observatório Militar da Praia Vermelha. (2020). DQBRN e Precursores - Clipagem de Notícias. Rio de Janeiro, RJ: Autor. Recuperado de http://ompv. eceme.eb.mil.br/masterpage_assunto.php?id=210

Observatório Militar da Praia Vermelha. (2020a). DQBRN e Precursores - Clipagem de Notícias Semana 1. Rio de Janeiro, RJ: Autor. Recuperado de_http://ompv.eceme.eb.mil.br/docs/dqbrn/ SEM01_31_12ate05_01.pdf

Observatório Militar da Praia Vermelha. (2020b). DQBRN e Precursores - Clipagem de Notícias Semana 2. Rio de Janeiro, RJ: Autor. Recuperado 
de_http://ompv.eceme.eb.mil.br/docs/dqbrn/ SEM02_06_01ate12_01.pdf

Observatório Militar da Praia Vermelha. (2020c). $D Q B R N$ e Precursores - Clipagem de Notícias Semana 3. Rio de Janeiro, RJ: Autor. Recuperado de_http://ompv.eceme.eb.mil.br/docs/dqbrn/ SEM03_13_01ate19_01.pdf

Observatório Militar da Praia Vermelha. (2020d). $D Q B R N$ e Precursores - Clipagem de Notícias Semana 5. Rio de Janeiro, RJ: Autor. Recuperado de_http://ompv.eceme.eb.mil.br/docs/dqbrn/ SEM05_27_01ate02_02.pdf

Observatório Militar da Praia Vermelha. (2020e). $D Q B R N$ e Precursores - Clipagem de Notícias Semana 11. Rio de Janeiro, RJ: Autor. Recuperado de http://ompv.eceme.eb.mil.br/docs/dqbrn/ SEM11_09_03ate15_03.pdf

Observatório Militar da Praia Vermelha. (2020f). $D Q B R N$ e Precursores - Clipagem de Notícias Semana 9. Rio de Janeiro, RJ: Autor. Recuperado de_http://ompv.eceme.eb.mil.br/docs/dqbrn/ SEM09_24_02ate01_03.pdf

Observatório Militar da Praia Vermelha. (2020g). $D Q B R N$ e Precursores - Clipagem de Notícias Semana 10. Rio de Janeiro, RJ: Autor. Recuperado de_http://ompv.eceme.eb.mil.br/docs/dqbrn/ SEM10_02_03ate08_03.pdf

Observatório Militar da Praia Vermelha. (2020h). $D Q B R N$ e Precursores - Clipagem de Notícias Semana 12. Rio de Janeiro, RJ: Autor. Recuperado de_http://ompv.eceme.eb.mil.br/docs/dqbrn/ SEM12_16_03ate22_03.pdf

Observatório Militar da Praia Vermelha. (2020i). $D Q B R N$ e Precursores - Clipagem de Notícias Semana 14. Rio de Janeiro, RJ: Autor. Recuperado de_http://ompv.eceme.eb.mil.br/docs/dqbrn/ SEM14_30_03ate05_04.pdf

Observatório Militar da Praia Vermelha. (2020j). $D Q B R N$ e Precursores - Clipagem de Notícias Semana 16. Rio de Janeiro, RJ: Autor. Recuperado de_http://ompv.eceme.eb.mil.br/docs/dqbrn/ SEM16_13_04ate19_04.pdf

Operação COVID-19. (2020, 30 de março). Militares realizam treinamento em defesa nuclear, biológica, química e radiológica para operação COVID-19.
Recuperado de https://operacaocovid19.defesa. gov.br/noticias/noticia/770-militares-realizamtreinamento-em-defesa-nuclear-biologica-quimicae-radiologica-para-operacao-covid-19

Organização Mundial da Saúde. (2005). International Health Regulations (2nd. Ed.). Geneva, Switzerland: Autor. Recuperado de http://portal.anvisa.gov.br/ documents/375992/4011173/9789241580410_eng. pdf/36b8b474-c10f-4433-82d4-18a04bc5a736

Organização Mundial da Saúde. (2020a, 21 de fevereiro). Coronavirus disease 2019 (COVID-19) (Situation Report, 32). Geneva, Switzerland: Autor. Recuperado de https://www.who.int/docs/defaultsource/coronaviruse/situation-reports/20200221sitrep-32-COVID-19.pdf?sfvrsn=4802d089_2

Organização Mundial da Saúde. (2011, maio). Disaster Risk Management for Health: overview. Geneva, Switzerland: Autor. Recuperado de https://www.who. int/hac/events/drm_fact_sheet_overview.pdf

Tannenwald, N. (1999). The nuclear taboo: The United States and the normative basis of nuclear non-use. International organization, 53(3), 433-468.

Portaria ANVISA no 74, de 27 de janeiro de 2020. (2020). Dispõe sobre a criação de Grupo de Emergência em Saúde Pública para condução das ações referentes ao Novo Coronavírus (NCoV). Brasília, DF: Ministério da Saúde.

Portaria $n^{\circ} 2.952$, de 14 de dezembro de 2011. (2011). Regulamenta, no âmbito do Sistema Único de Saúde (SUS), o Decreto $\mathrm{n}^{\circ}$ 7.616, de 17 de novembro de 2011, que dispõe sobre a declaração de Emergência em Saúde Pública de Importância Nacional (ESPIN) e institui a Força Nacional do Sistema Único de Saúde (FN-SUS). Brasília, DF: Ministério da Saúde.

Portaria $n^{\circ} 30$, de 7 de julho de 2005. (2005). Institui o Centro de Informações Estratégicas em Vigilância em Saúde, define suas atribuições, composição e coordenação. Brasília, DF: Ministério da Saúde.

Portaria $n^{\circ} 454$, de 20 de março de 2020. (2020). Declara, em todo território nacional, o estado de transmissão comunitária do coronavírus (COVID-19). Brasília, DF: Ministério da Saúde.

Portaria $n^{\circ}$ 639, de 31 de março de 2020. (2020). Dispõe sobre a Ação Estratégica "O Brasil Conta Comigo - Profissionais da Saúde", voltada à capacitação e ao cadastramento de profissionais da 
área de saúde, para o enfrentamento à pandemia do coronavírus (COVID-19). Brasília, DF: Ministério da Saúde.

Portaria $n^{\circ} 188$, de 3 de fevereiro de 2020. (2020). Declara Emergência em Saúde Pública de importância Nacional (ESPIN) em decorrência da Infecção Humana pelo novo Coronavírus (2019nCoV). Brasília, DF.

Programa das Nações Unidas para o Desenvolvimento. (2020). Gestão de Riscos e Desastres Naturais. Brasília, DF: Autor. Recuperado de https://www. br.undp.org/content/brazil/pt/home/projects/riscoe-desastres.html

Programa das Nações Unidas para o Meio Ambiente. (2020, 03 de março). Coronavirus outbreak highlights need to address threats to ecosystems and wildlife. Recuperado de https://www.unenvironment.org/ news-and-stories/story/coronavirus-outbreakhighlights-need-address-threats-ecosystems-andwildlife

Quarantelli, E. L., Lagadec, P., \& Boin, A. (2007). A heuristic approach to future disasters and crises: new, old, and in-between types. In H. Rodriguez, E. L. Quarantelli, R. Dynes (Eds.), Handbook of disaster research (pp. 16-41). New York, NY: Springer.

Resolução no 588, de 12 de julho de 2018. (2018). Fica instituída a Política Nacional de Vigilância em Saúde (PNVS), aprovada por meio desta resolução. Brasília, DF: Conselho Nacional de Secretarias Municipais de Saúde.

Reuters. (2020, 26 de maio). Special Report: Bolsonaro brought in his generals to fight coronavirus. Brazil is losing the battle. Recuperado de https://www.reuters. com/article/us-health-coronavirus-brazil-responsesp-idUSKBN2321DU
Rumbach, A. (2016). Decentralization and small cities: Towards more effective urban disaster governance? Habitat International, 52(2015), 35-42.

Sabatier, P. A. (Ed.). (2007). Theories of the Policy Process. Boulder, Colorado: Westview Press.

Secretaria Nacional de Defesa Civil. (2007). Política Nacional de Defesa Civil. Brasília, DF: Ministério da Integração Nacional.

Stoker, G. (1998). Governance as theory: five propositions. International Social Science Journal, 50, 17-28.

Tierney, K. (2012). Disaster Governance: Social, Political, and Economic Dimensions. Annual Review of Environment and Resources, 37(1), 341-363.

Wisner, B, Adams, J. (2002). Environmental health in emergencies and disasters: a practical guide. Geneva, Switzerland: World Health Organization. Recuperado de https://apps.who.int/iris/handle/10665/42561

United Nations Office for Disaster Risk Reduction. (2009). 2009 UNISDR terminology on disaster risk reduction. Recuperado de https://www.undrr.org/ publication/2009-unisdr-terminology-disaster-riskreduction

United Nations Office for Disaster Risk Reduction. (2015). Marco de Sendai para la Reducción del Riesgo de Desastres 2015-2030. Recuperado de https://www.preventionweb.net/files/43291_ spanishsendaiframeworkfordisasterri.pdf

Zurita, M. de L. M., Cook, B., Harms, L., \& March, A. (2015). Towards New Disaster Governance: Subsidiarity as a Critical Tool. Environmental Policy and Governance, 25(6), 386-398. 


\section{Karina Furtado Rodrigues}

https://orcid.org/0000-0001-9330-6399

Doutora em Administração pela Escola Brasileira de Administração Pública e de Empresas da Fundação Getulio Vargas (FGV EBAPE); Professora do Programa de Pós-Graduação em Ciências Militares (PPGCM) do Instituto Meira Mattos, na Escola de Comando e Estado-Maior do Exército (IMM/ECEME).

E-mail: karinafrodrigues@gmail.com

\section{Mariana Montez Carpes}

https://orcid.org/0000-0002-7581-2973

Doutora em Relações Internacionais pela Universidade de Hamburgo; Professora do Programa de PósGraduação em Ciências Militares (PPGCM) do Instituto Meira Mattos, na Escola de Comando e Estado-Maior do Exército (IMM/ECEME). E-mail: mariana.montez.carpes@gmail.com

\section{Carolina Gomes Raffagnato}

https://orcid.org/0000-0001-7426-3864

Bacharel em Engenharia Química pela Universidade Federal Rural do Rio de Janeiro; Mestranda no Programa de Pós-Graduação em Ciências Militares (PPGCM) do Instituto Meira Mattos, na Escola de Comando e EstadoMaior do Exército (IMM/ECEME). E-mail: carolina.raffagnato@gmail.com 